Check for updates

Cite this: RSC Adv., 2018, 8, 9152

\title{
Supported cobalt catalysts for the selective hydrogenation of ethyl levulinate to various chemicals $\uparrow$
}

\author{
Youliang Cen, (DD ab Shanhui Zhu, (D) *a Jing Guo, ${ }^{\text {ab }}$ Jiachun Chai, $^{\text {ab }}$ Weiyong Jiao, ${ }^{a}$ \\ Jianguo Wang (D) and Weibin Fan (D) *a
}

\begin{abstract}
A highly active and selective cobalt catalyst was developed for the hydrogenation of biomass-derived ethyl levulinate (EL) to $\gamma$-valerolactone (GVL), ethyl 4-hydroxypentanoate (EHP), 1,4-pentanediol (1,4-PDO) and 2-methyltetrahydrofuran (2-MTHF), which are considered to be value-added chemicals and important biofuels. The effects of reaction time, reaction temperature, catalyst amount and solvent on its catalytic performance were investigated. In addition, the reaction pathway was studied as well. It was found that the selectivity of GVL, 1,4-PDO and 2-MTHF on $\mathrm{Co} / \mathrm{ZrO}_{2}$ can be easily tuned by changing reaction conditions, and can reach as high as $94 \%, 78 \%$ and $77 \%$, respectively. The product selectivity is also significantly affected by the catalyst support. With SBA-15 as the support, the selectivity of EHP can reach $90 \%$. Moreover, $\mathrm{Co} / \mathrm{ZrO}_{2}$ gave an extraordinarily high GVL productivity of $1.50 \mathrm{~mol} \mathrm{gmetal}{ }^{-1} \mathrm{~h}^{-1}$ and displayed excellent stability and reusability. Interestingly, coke has a positive effect on the enhancement of GVL yield. AL dimers and trimers were identified as the coke species in the hydrogenation of EL. As far as we know, this is the first work conducting the flexible transformation of EL on cobalt catalysts.
\end{abstract}

Received 10th February 2018 Accepted 26th February 2018

DOI: 10.1039/c8ra01316k

rsc.li/rsc-advances conversion of EL is less strict for the catalyst. The strong acidity of LA will severely destroy the support such as zeolites and leach the active metal sites. ${ }^{7}$ In addition, it also heavily corrodes equipment. EL yielded from direct alcoholysis is obviously higher than that of LA from hydrolysis due to substantial suppression of humins formation, and EL is easier to be separated in alcohol medium. ${ }^{8}$

Several metal catalysts have been reported to be active for the hydrogenation of LA and its ester to GVL. Homogeneous catalysts such as $\mathrm{Ru}(\mathrm{acac})_{3}$ in combination with tris(3sulfonatophenylphosphine) (TPPTS) or $\mathrm{PBu}_{3}$, iridium complexes and Shvo catalyst give very high conversion and GVL yield. ${ }^{9}$ However, the complexity in the ligand synthesis, together with the difficulty of catalyst recovery and recycling, greatly lowers the application potential of homogeneous catalysts in commercial applications. To solve these problems, heterogeneous catalysts have been successfully developed, and a series of supported noble metal catalysts such as $\mathrm{Ru} / \mathrm{C}, \mathrm{Ru} / \mathrm{SiO}_{2}, \mathrm{Ru}$ / $\mathrm{Al}_{2} \mathrm{O}_{3}, \mathrm{Ru} / \mathrm{TiO}_{2}, \mathrm{RuCs} / \mathrm{Al}_{2} \mathrm{O}_{3}, \mathrm{RuRe} / \mathrm{C}, \mathrm{Au} / \mathrm{ZrO}_{2}, \mathrm{AuPd} / \mathrm{TiO}_{2}$ and $\mathrm{PdNb} / \mathrm{AC}$ exhibit excellent performance. ${ }^{4 b, 10}$ However, the high cost and limited reserve of noble metals necessitate the development of abundant non-noble metal catalysts.

In this aspect, RANEY® Ni, Hf-ATMP, Zr-MOFs, Zr-beta and $\mathrm{ZrO}_{2}$ have been demonstrated to be effective for the transformation of LA and its esters to GVL through catalytic transfer hydrogenation process. ${ }^{11}$ In addition, supported non-noble metal catalysts $\left(\mathrm{Cu}\right.$, Co and $\mathrm{Ni}$ ) and reduced $\mathrm{Co}_{3} \mathrm{O}_{4}$ also present moderate ability in activating LA and its esters. ${ }^{7 a, 12}$ 
Nevertheless, the GVL formation rate is rather low, and the highest rate reported by Chia et al. ${ }^{11 b}$ reached only $6.5 \mathrm{mmol}_{\mathrm{GVL}}$ $\mathrm{g}_{\text {cat }}{ }^{-1} \mathrm{~h}^{-1}$ over $\mathrm{ZrO}_{2}$. Particularly, relatively higher reaction temperature is required to obtain high activity over non-noble metals than over noble ones.

The intermediate for hydrogenation EL to GVL has been identified as ethyl 4-hydroxypentanoate (EHP), which is a kind of chiral $\gamma$-hydroxy ester and an important bioactive molecule. It is currently made by fermenting and chemoenzymatic protocols. ${ }^{13}$ GVL can be further hydrogenated to highly valuable 1,4pentanediol (1,4-PDO) and 2-methyltetrahydrofuran (2-MTHF). Biogenic diols are interesting building blocks for biodegradable polyesters and other polymeric materials. ${ }^{14}$ 2-MTHF is advocated as a bioderived "green" solvent and a component of Pseries fuels in future. ${ }^{15}$ Geilen et al. ${ }^{14 a}$ have demonstrated that homogeneous $\mathrm{Ru}(\mathrm{acac})_{3}$ in combination with phosphine ligands and acidic additives can selectively convert LA into GVL, 1,4-PDO and 2-MTHF. Despite its high activity, this catalyst system is highly expensive and shows severe limitation of homogeneous catalysts, and hence, possibly influencing product quality. Thus, various homogeneous catalysts were integrated with heterogeneous ones, ${ }^{16}$ and most of researches devote to production of one type of chemical. Concerning preparation of 1,4-PDO, supported noble metal catalysts were generally employed, including $\mathrm{Ir}-\mathrm{MoO}_{x} / \mathrm{SiO}{ }_{2}, \mathrm{Rh}-\mathrm{MoO}_{x} / \mathrm{SiO}_{2}$, $\mathrm{RuRe} / \mathrm{C}$ and $\mathrm{Pt}-\mathrm{Mo} / \mathrm{HAP} .{ }^{17}$ With respect to production of 2 MTHF, Pt-Mo/H- $\beta$ and $\mathrm{Ru}-\mathrm{N}$-triphos complexes are only reported to be active..$^{\mathbf{1 5 , 1 8}}$ Recently, it is very interesting that Yang et al. ${ }^{19}$ achieve transfer hydrogenation of methyl levulinate into GVL, 1,4-PDO and 1-pentanol (1-PAO) over $\mathrm{Cu} / \mathrm{ZrO}_{2}$ although their selectivities only get to $75 \%, 39 \%$ and $13.8 \%$, respectively, under optimal reaction conditions, because it shows the possibility for controllable transformation of LA and its ester over non-noble metal heterogeneous catalyst.

In this context, we prepare a cobalt catalyst of $\mathrm{Co} / \mathrm{ZrO}_{2}$ that can flexibly hydrogenate EL in 1,4-dioxane solvent to GVL, 1,4PDO and 2-MTHF with selectivity of $94 \%, 78 \%$ and $77 \%$, respectively. A change of the support to SBA-15 leads to formation of $90 \%$ EHP. We demonstrate for the first time that the efficient non-noble metal cobalt catalyst for the flexible transformation of EL. It is interesting that deposition of appropriate amounts of coke species has a positive effect on the formation of GVL.

\section{Experimental section}

\subsection{Materials}

$\mathrm{Co}\left(\mathrm{NO}_{3}\right)_{2} \cdot 6 \mathrm{H}_{2} \mathrm{O}$, methanol, ethanol, 1-propanol, 2-propanol, 1butanol, 1-pentanol, cyclohexane, benzene and tetrahydrofuran were supplied by Sinopharm Chem. Reagent Co., Ltd. 1,4Dioxane, ethyl levulinate, $\alpha$-angelica lactone and $\operatorname{bis}(2$ methoxyethyl)ether were all purchased from Aladdin. 1,4-Pentanediol and $\gamma$-valerolactone was bought from Sigma-Aldrich and Damas-beta respectively. The above-mentioned chemicals were all of analytical grade and used as received without further purification. $\mathrm{ZrO}_{2}$ (Jiangsu Qianye Co., Ltd, China), $\mathrm{TiO}_{2}$ (Degussa P25), $\gamma-\mathrm{Al}_{2} \mathrm{O}_{3}$ (Shandong aluminum Co., Ltd, China),
SBA-15 (Nanjing XFNANO Mater. Technol. Co., Ltd.), and montmorillonite (MMT) K-10 (Aladdin) were used as supports.

\subsection{Catalyst preparation}

All the supported Co catalysts were prepared by the wetness impregnation method. Prior to the impregnation, the support was vacuum dried at $120{ }^{\circ} \mathrm{C}$ overnight. The dried support was dispersed in cobalt nitrate aqueous solution under vigorous stirring condition for $24 \mathrm{~h}$. This is followed by directly drying at $100{ }^{\circ} \mathrm{C}$ for $10 \mathrm{~h}$, and further calcining at $500{ }^{\circ} \mathrm{C}$ for $4 \mathrm{~h}$ in air.

\subsection{Catalyst characterization}

$\mathrm{N}_{2}$ adsorption-desorption isotherms were measured at $-196{ }^{\circ} \mathrm{C}$ on a Micromeritics TriStar 3000 instrument. BET surface area and $\mathrm{BJH}$ pore size distribution were calculated based on the desorption branch of the isotherms.

The temperature-programmed desorption of ammonia ( $\mathrm{NH}_{3}$-TPD) was performed on a Micromeritics AutoChem II 2920. Typically, $0.1 \mathrm{~g}$ sample was first pretreated at $400{ }^{\circ} \mathrm{C}$ for 30 min in Ar flow. Then, it was flushed with $\mathrm{NH}_{3}$ up to adsorptive saturation after being cooled to $100{ }^{\circ} \mathrm{C}$. After that, the sample was heated to $600{ }^{\circ} \mathrm{C}$ at a rate of $10^{\circ} \mathrm{C} \mathrm{min}$, and the desorbed $\mathrm{NH}_{3}$ was monitored by a thermal conductivity detector (TCD). The $\mathrm{H}_{2}$-TPR experiment was carried out in the same apparatus as that used for $\mathrm{NH}_{3}$-TPD. The sample was first pretreated at $500{ }^{\circ} \mathrm{C}$ for $30 \mathrm{~min}$ in Ar flow. Then, it was exposed to $10 \% \mathrm{H}_{2}-\mathrm{Ar}$ flow after being cooled down to $40{ }^{\circ} \mathrm{C}$. Finally, the temperature was raised to $800{ }^{\circ} \mathrm{C}$ at a rate of $5^{\circ} \mathrm{C} \mathrm{min}^{-1}$, and the amount of consumed $\mathrm{H}_{2}$ was monitored with a TCD. X-ray photoelectron spectra (XPS) were measured on a Kratos Axis Ultra DLD spectrometer equipped with a monochromated AlK $\alpha$ radiation source and a multichannel detector. All the binding energies were calibrated with adventitious C 1 s peak at $284.8 \mathrm{eV}$.

The cobalt content was determined by an inductively coupled plasma-atomic emission spectrometer (ICP-AES, Thermo iCAP 6300). Powder X-ray diffraction (XRD) patterns were collected on a Rigaku MiniFlex II desktop X-ray diffractometer with monochromated $\mathrm{CuK} \alpha$ radiation $(0.154 \mathrm{~nm}, 30 \mathrm{kV}$, and $15 \mathrm{~mA}$ ) at a scanning speed of $4^{\circ} \mathrm{min}^{-1}$. Transmission electron microscopy (TEM) images were taken on a fieldemission transmission electron microscope (JEM-2100F) at an acceleration voltage of $200 \mathrm{kV}$. Prior to the measurements, the sample powders were dispersed into ethanol by ultrasonicating for $15 \mathrm{~min}$, and dropped onto copper grids. Co/SBA-15 sample was embedded in a polymeric resin and polished to $20 \mathrm{~nm}$ thick in the middle of the sample using precision ion polishing system (Gatan 691). The average Co particle sizes were determined by counting more than 200 particles from several TEM images.

Thermal gravimetric analyses (TGA) of used catalysts were carried out on a Rigaku Thermo plus Evo TG 8120 instrument. The sample was initially heated to $160{ }^{\circ} \mathrm{C}$ at a rate of $10{ }^{\circ} \mathrm{C} \mathrm{min}^{-1}$ and kept for $30 \mathrm{~min}$. Then, it was further heated to $600{ }^{\circ} \mathrm{C}$ at the same rate in air flow $\left(30 \mathrm{~mL} \mathrm{~min}^{-1}\right)$. The deposited carbonaceous species extracted with methyl isobutyl ketone (MIBK) after destroying the catalyst structure with HF (40 wt\%) 
Table 1 Structure and physical parameters of different Co-based catalysts

\begin{tabular}{llccccc}
\hline Sample & Co loading $^{a}(\mathrm{wt} \%)$ & $S_{\text {BET }}\left(\mathrm{m}^{2} \mathrm{~g}^{-1}\right)$ & $d_{\text {pore }}(\mathrm{nm})$ & $\mathrm{Co}_{3} \mathrm{O}_{4}$ particle size $^{b}(\mathrm{~nm})$ & Cobalt dispersion $^{c}$ & $\mathrm{NH}_{3}$ uptake $^{d} \mathrm{mmol} \mathrm{g}^{-1}$ \\
\hline $\mathrm{Co} / \gamma-\mathrm{Al}_{2} \mathrm{O}_{3}$ & 9.0 & 127.7 & 8.4 & 9.1 & 14.1 & 0.31 \\
$\mathrm{Co} / \mathrm{SBA}^{-15}$ & 9.2 & 472.5 & 7.8 & 10.5 & 12.2 & 0.6 \\
$\mathrm{C} / \mathrm{TiO}_{2}$ & 9.2 & 31.0 & 37.4 & 14.8 & 8.1 & 0.17 \\
$\mathrm{Co} / \mathrm{MMT}$ & 8.8 & 80.2 & 7.8 & 15.8 & 6.4 & 0.13 \\
$\mathrm{Co} / \mathrm{ZrO}_{2}$ & 9.6 & 38.1 & 8.4 & 19.9 & 0.18
\end{tabular}

${ }^{a}$ Determined by ICP. ${ }^{b}$ Estimated by Scherrer equation, according to the (311) reflection of $\mathrm{Co}_{3} \mathrm{O}_{4} \cdot{ }^{c}$ Co dispersion is calculated by $D=96 / d$, where

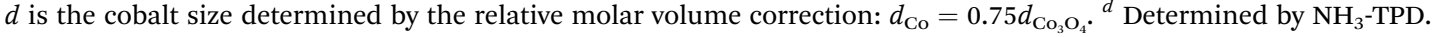

were analyzed by the positive-ion ESI mass spectroscopy (Bruker micrOTOF-Q III). The IR spectra in the range of $400-4000 \mathrm{~cm}^{-1}$ were recorded on a Bruker Vertex 70 FTIR spectrometer using the conventional $\mathrm{KBr}(99 \mathrm{wt} \%)$ pellet method.

\subsection{Catalyst test}

All the reactions were carried out in a $50 \mathrm{~mL}$ high-pressure autoclave equipped with a magnetic stirrer. Before reaction, $0.1 \mathrm{~g}$ catalyst was reduced at $500{ }^{\circ} \mathrm{C}$ for $2 \mathrm{~h}$ in $10 \mathrm{vol} \% \mathrm{H}_{2}-\mathrm{Ar}$ flow. It was quickly added into the autoclave together with $17.4 \mathrm{mmol}$ ethyl levulinate and $15 \mathrm{~mL}$ solvent. The autoclave was purged with $\mathrm{H}_{2}$ for three times, and charged of $4.0 \mathrm{MPa} \mathrm{H}_{2}$. The reaction was stopped by quickly cooling the autoclave in an ice water bath. The catalyst stability was investigated by the regeneration method. The spent sample was magnetically separated from the reaction mixture, thoroughly washed with corresponding solvent, and directly reused under identical reaction conditions. The catalyst was regenerated by calcining at 500 or $550{ }^{\circ} \mathrm{C}$ for $2 \mathrm{~h}$ in static air and reducing at $500{ }^{\circ} \mathrm{C}$ for $2 \mathrm{~h}$ in $10 \mathrm{vol} \% \mathrm{H}_{2}-\mathrm{Ar}$.

The reaction products were analyzed by a Shimadzu GC2014C gas chromatograph equipped with a DB-WAX column $(30 \mathrm{~m} \times 0.53 \mathrm{~mm} \times 0.25 \mu \mathrm{m})$ and a flame ionization detector (FID). The unknown products were identified with GC-MS (Shimadzu QP2010 Ultra) by comparing with authentic chemicals. The products were also qualitatively analyzed by the positive-ion ESI mass spectroscopy (Bruker micrOTOF-Q III) and NMR spectroscopy (Bruker AV-III $400 \mathrm{MHz}$ NMR spectrometer). The product amount was quantitatively determined by calibrated area normalization. In the experiments for investigating the effect of solvents, the EL conversion and GVL yield were calculated on the basis of GC analysis results obtained with bis(2-methoxyethyl)ether as internal standard.

\section{Results and discussion}

\subsection{Characterization of the catalysts and hydrogenation activity}

First, the effect of support on the catalytic performance was investigated. Fig. S1† shows that all the samples contain sole crystalline Co phase, viz. spinel $\mathrm{Co}_{3} \mathrm{O}_{4}$ (JCPDS 42-1467). Table 1 shows the $\mathrm{Co}_{3} \mathrm{O}_{4}$ particle size, as calculated by the Scherrer equation from the most intense peak at $2 \theta=36.8^{\circ}$, of different samples. The Co size calculated by the equation of $d_{\mathrm{Co}}=$ $0.75 d_{\mathrm{Co}_{3} \mathrm{O}_{4}}$ is consistent with that of TEM results ${ }^{20}$ (Fig. 1). The metal dispersions in the calcined catalysts are estimated on the basis of cobalt size. ${ }^{20}$ The formation of Co species in the reduced samples, e.g. $\mathrm{Co} / \mathrm{ZrO}_{2}$, can be verified by its lattice planes of Co (200) and (111) (Fig. 1h and i). Fig. 1a-d shows that Co nanoparticles are highly dispersed on $\gamma-\mathrm{Al}_{2} \mathrm{O}_{3}$ and well confined in the mesopores of SBA- $15,{ }^{21}$ while much larger Co particles are present in the other supports such as $\mathrm{TiO}_{2}, \mathrm{MMT}$ and $\mathrm{ZrO}_{2}$. Thus, $\mathrm{Co} / \gamma-\mathrm{Al}_{2} \mathrm{O}_{3}$ and $\mathrm{Co} / \mathrm{SBA}-15$ have higher dispersions than the other samples. Table 1 shows that no distinct relationship exists between BET surface area and Co dispersion, indicating that Co dispersion is not significantly affected by the BET surface area of catalysts.

Fig. 2a shows the $\mathrm{H}_{2}$-TPR profiles of different catalysts. Two peaks were observed for all the samples. The peak between 200 and $350{ }^{\circ} \mathrm{C}$ is attributed to the reduction of $\mathrm{Co}_{3} \mathrm{O}_{4}$ to $\mathrm{CoO}$, and that in the range of $300-550{ }^{\circ} \mathrm{C}$ is due to the reduction of $\mathrm{CoO}$ to metallic Co. As for the reduction peaks observed at temperature higher than $550{ }^{\circ} \mathrm{C}$ in the profiles of $\mathrm{Co} / \mathrm{Al}_{2} \mathrm{O}_{3}, \mathrm{Co} / \mathrm{SBA}-15$ and $\mathrm{Co} / \mathrm{MMT}$ can be assigned to the reduction of cobalt species strongly interacted with support. ${ }^{22}$ Metallic $\mathrm{Co}^{0}$ was proved to be the active species in the hydrogenation reaction. ${ }^{12 d}$ Clearly, the $\mathrm{Co}_{3} \mathrm{O}_{4}$ species in the $\mathrm{Co} / \mathrm{ZrO}_{2}$ and $\mathrm{Co} / \mathrm{TiO}_{2}$ are easily reduced,

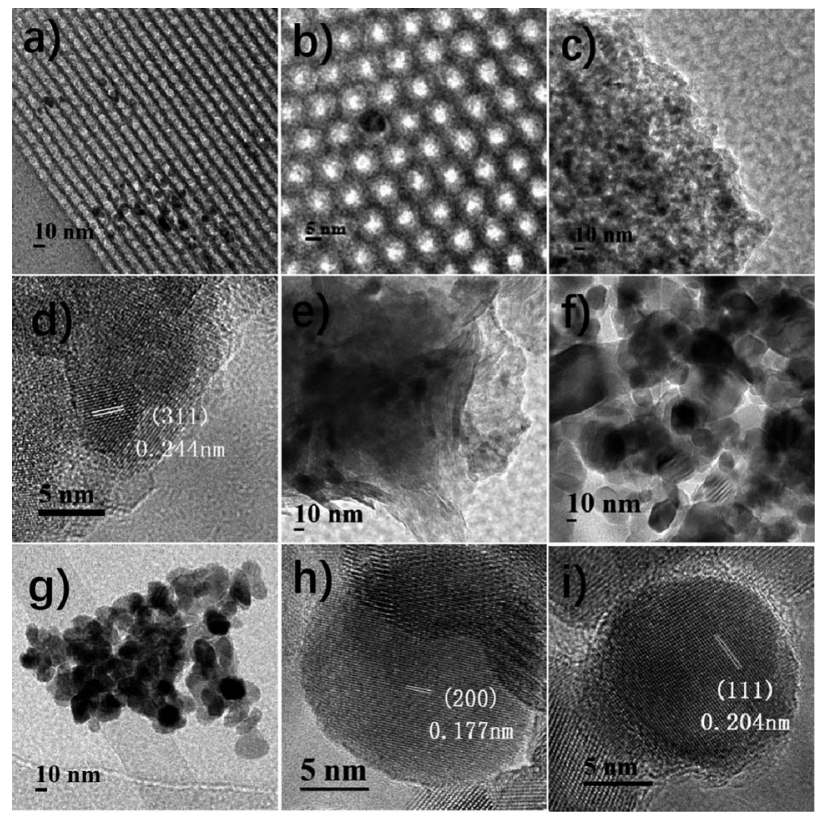

Fig. 1 TEM and HRTEM images of reduced Co/SBA-15 (a and b), $\mathrm{Co} / \gamma-$ $\mathrm{Al}_{2} \mathrm{O}_{3}$ (c and d), $\mathrm{Co} / \mathrm{MMT}$ (e), $\mathrm{Co} / \mathrm{TiO}_{2}$ (f), and $\mathrm{Co} / \mathrm{ZrO}_{2}$ (g-i). 

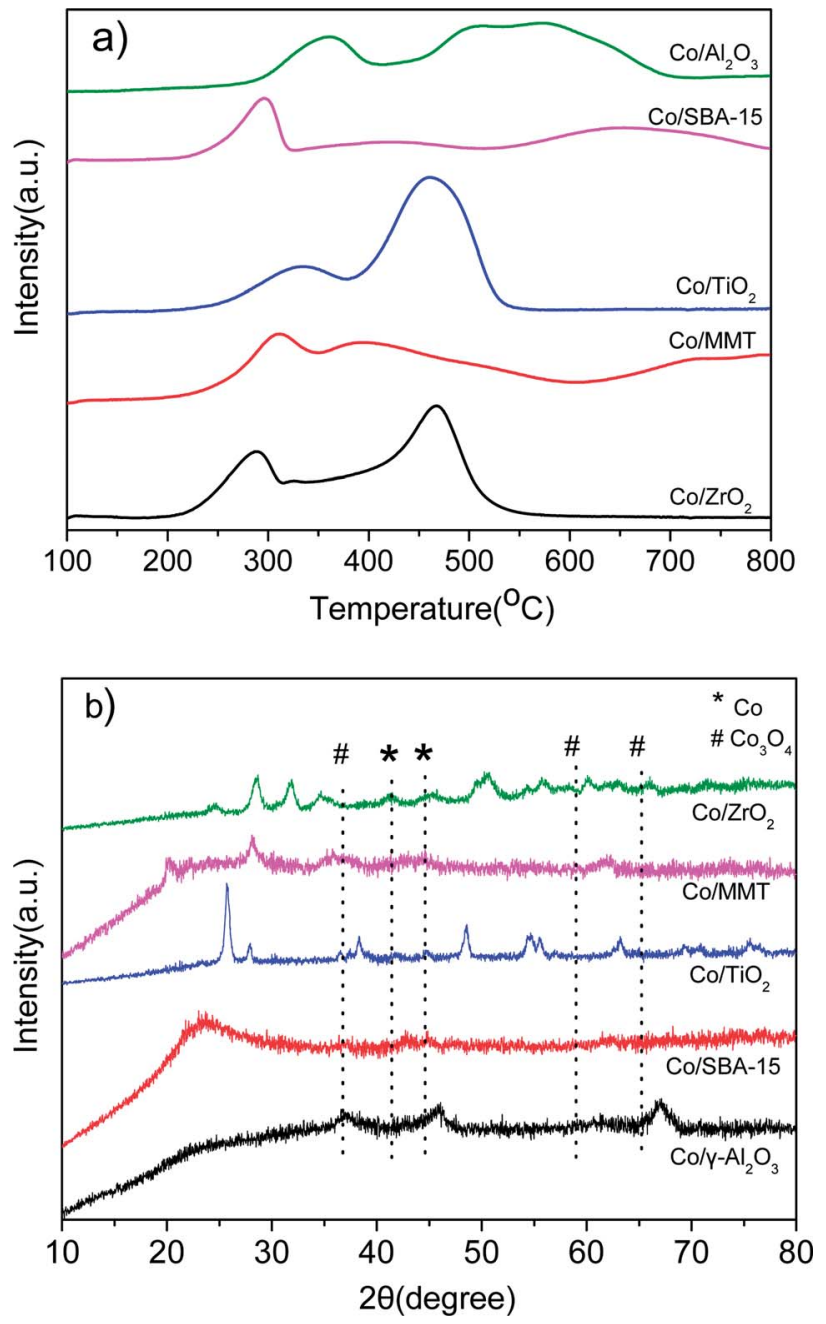

Fig. 2 (a) $\mathrm{H}_{2}$-TPR curves of the as-prepared Co-based catalysts; (b) XRD patterns of the reduced Co-based catalysts.

consequently giving larger amounts of active Co species. Fig. $2 \mathrm{~b}$ shows the XRD spectra of the reduced catalysts. The characteristic peaks of $\mathrm{Co}_{3} \mathrm{O}_{4}$ at $36.8^{\circ}, 59.4^{\circ}$ and $65.2^{\circ}$ nearly cannot be detected on $\mathrm{Co} / \mathrm{ZrO}_{2}$ and $\mathrm{Co} / \mathrm{TiO}_{2}$, and the peaks of $\mathrm{Co}$ at $41.7^{\circ}$ and $44.7^{\circ}$ (JCPDS 05-0727) can be seen clearly. There is no significant change of $\mathrm{Co} / \mathrm{Al}_{2} \mathrm{O}_{3}$ after reduction and the lattice planes of $\mathrm{Co}_{3} \mathrm{O}_{4}$ (111) can be observed in Fig. 1f. These results are in good consistent with the TPR profiles.

Fig. 3 shows that all the supported Co catalysts enabled a nearly total conversion of EL except that $\mathrm{Co} / \gamma-\mathrm{Al}_{2} \mathrm{O}_{3}$ obtained only $31.9 \%$ conversion. Interestingly, $\mathrm{Co} / \mathrm{ZrO}_{2}$ gave a GVL yield as high as $83.5 \%$, whereas Co/SBA- 15 catalyst exhibited the highest EHP yield of $57.1 \%$. This is probably due to their different acidity and reducibility of $\mathrm{Co}_{3} \mathrm{O}_{4}$ species. $\mathrm{Co} / \mathrm{ZrO}_{2}$ shows high reducibility of $\mathrm{Co}_{3} \mathrm{O}_{4}$ species and moderate acidity in dealcoholization process (Table 1), while Co/SBA-15 exhibits weak acidity. It has been reported that acid sites are beneficial to increase GVL yield. ${ }^{23}$ It should be noted that EHP was generated as byproducts, but it has not been definitely identified yet although it is a valueadded product. ${ }^{11 d, 24}$ We unambiguously confirmed the formation of EHP with ${ }^{1} \mathrm{H}$ and ${ }^{13} \mathrm{C}$ NMR as well as mass spectroscopy

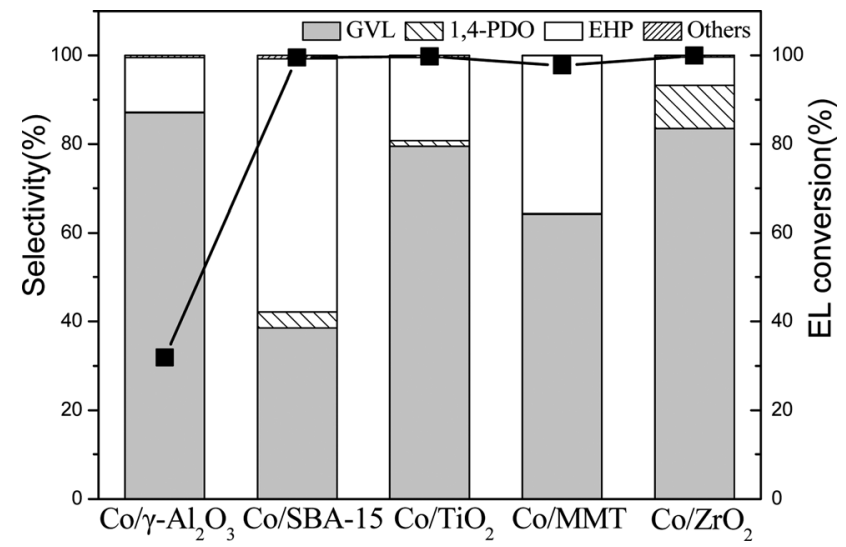

Fig. 3 Catalytic results for hydrogenation of EL in 1,4-dioxane over different catalysts (reaction conditions: $17.4 \mathrm{mmol} \mathrm{EL}, 15 \mathrm{~mL}$ 1,4dioxane, $190^{\circ} \mathrm{C}, 4 \mathrm{MPa} \mathrm{H}_{2}, 2 \mathrm{~h}$ and $0.1 \mathrm{~g}$ catalyst. Others mainly include 2-MTHF, 1-PAO, and 2-PAO).

(Fig. S2-S4 $\dagger$ ), and found that its yield was increased by lowering reaction temperature. At $160{ }^{\circ} \mathrm{C}$, the EHP yield obtained over $\mathrm{Co} /$ SBA-15 reached $90 \%$. To the best of our knowledge, this value is much higher than the reported results. ${ }^{13}$ Such a high EHP yield is due to the high dispersion of Co species on Co/SBA-15 and weak acidity of SBA-15.

\subsection{Effect of reaction conditions}

The influence of reaction conditions on the catalytic performance was investigated with $\mathrm{Co} / \mathrm{ZrO}_{2}$ as model catalysts as it gave the highest GVL yield. Fig. 4a shows that the selectivity of EHP drastically declined with the reaction time, while 1,4-PDO and 2-MTHF selectivity gradually increased to $23.2 \%$ and $11.8 \%$ respectively at $24 \mathrm{~h}$. The GVL selectivity quickly increased to $81.5 \%$ within one $1 \mathrm{~h}$, and then, maintained in the range of $83.5-86.7 \%$ between 2 and $5 \mathrm{~h}$. After that, it monotonically decreased with increasing reaction time.

Fig. 4b shows that 1,4-PDO selectivity linearly increases with increasing catalyst amount from 10 to $100 \mathrm{mg}$. This suggests that introduction of more amount of active Co species in the reaction system leads to formation of more 1,4-PDO. To confirm this hypothesis, $3.47 \mathrm{mmol} \mathrm{EL}$ (one fifth of normally added amount) was added into the reaction system (named as 100 $\mathrm{mg}^{-2}$ ). As expected, a very high 1,4-PDO yield $(45.4 \%)$ was obtained. However, it is strange that a further increase in the catalyst weight to $300 \mathrm{mg}$ contrarily decreased 1,4-PDO yield to $26.1 \%$, and large amounts of 2-MTHF was detected.

Thus, a new way needs to be developed for further enhancing the production of 1,4-PDO. It was found that the 1,4-PDO yield considerably increased to $59 \%$ with increasing reaction pressure to $6 \mathrm{MPa}$ (Fig. 4c), and could be further increased to nearly $74 \%$ by prolonging reaction time to $8 \mathrm{~h}$. It reached as high as $78 \%$ at $8 \mathrm{~h}$ when the $\mathrm{H}_{2}$ pressure was increased to $8 \mathrm{MPa}$.

It is worth pointing out that $\mathrm{Co} / \mathrm{ZrO}_{2}$ can selectively catalyze hydrogenolysis of EL into not only GVL and 1,4-PDO but also 2MTHF. Table 2 shows that the increase of reaction temperature to $230{ }^{\circ} \mathrm{C}$ enhanced 2-MTHF selectivity to $76.7 \%$ (entry 1 ) due to promotion of the dehydration of diol to cyclic ether. ${ }^{25}$ 

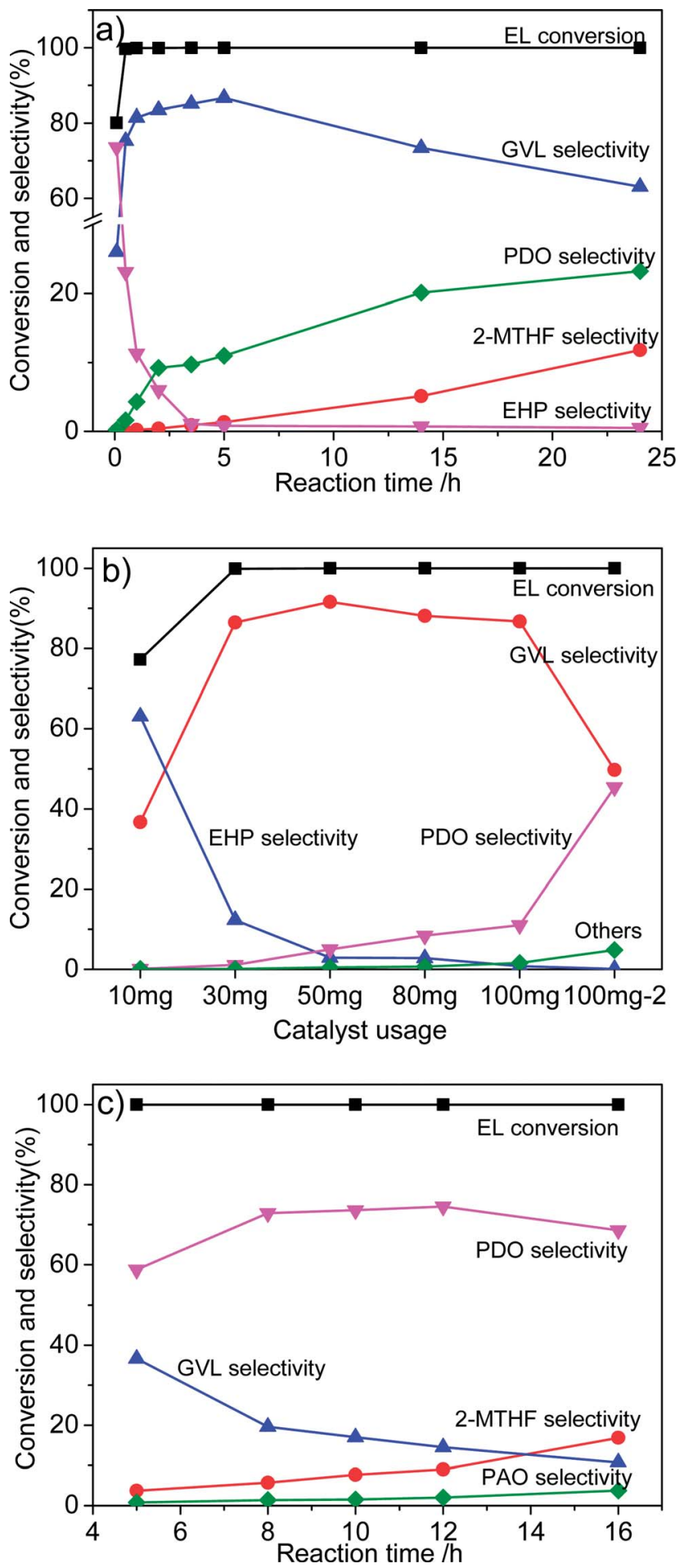

Fig. 4 Effect of reaction conditions on the catalytic performance of $\mathrm{Co} / \mathrm{ZrO}_{2}$ for hydrogenation of EL. (a) $17.4 \mathrm{mmol} \mathrm{EL}, 15 \mathrm{~mL}$ 1,4-dioxane, $190{ }^{\circ} \mathrm{C}, 4 \mathrm{MPa} \mathrm{H}{ }_{2}$ and $0.1 \mathrm{~g} \mathrm{Co} \mathrm{ZrO}_{2}$; (b) $17.4 \mathrm{mmol} \mathrm{EL}$ (the $100 \mathrm{mg}^{-2}$ in the horizontal ordinate represents addition of $3.47 \mathrm{mmol} E \mathrm{EL}), 15 \mathrm{~mL}$ 1,4-dioxane, $190^{\circ} \mathrm{C}, 5 \mathrm{~h}$ and $4 \mathrm{MPa} \mathrm{H}$; (c) $3.47 \mathrm{mmol} \mathrm{EL}, 15 \mathrm{~mL}$ 1,4dioxane, $190{ }^{\circ} \mathrm{C}, 6 \mathrm{MPa} \mathrm{H}$ and $0.1 \mathrm{~g} \mathrm{Co}_{2} \mathrm{ZrO}_{2}$.

\subsection{Reaction route for the conversion of EL}

In order to illustrate the reaction process of EL hydrogenation, conversion of GVL, 1,4-PDO, 1-PAO, 2-pentanol (2-PAO) and 2MTHF over $\mathrm{Co} / \mathrm{ZrO}_{2}$ in the presence of $\mathrm{H}_{2}$ were explored under the same conditions as hydrogenation of EL. Table 2 shows that 1,4-PDO was mainly produced from GVL at $190{ }^{\circ} \mathrm{C}$ with a selectivity of nearly $80 \%$ (entry 2 ). This is different from the results attained on $\mathrm{Ru} / \mathrm{H}-\mathrm{ZSM}-5, \mathrm{Ru} / \mathrm{SBA}-15-\mathrm{SO}_{3} \mathrm{H}, \mathrm{Pt} / \mathrm{MFI}$, and Co@ZSM-5 that petanoic acid (PA) is primarily generated via ring opening of $\mathrm{GVL}^{7 b, 26}$ due to the weaker acidity of $\mathrm{ZrO}_{2}$ than of zeolites and sulfonated SBA-15 supports.

High temperature promotes the dehydration of 1,4-PDO to 2MTHF. Table 2 shows that MTHF selectivity reached $74.4 \%$ at $230{ }^{\circ} \mathrm{C}$ (entry 3). Although 1,4-PDO, like all diols, can also convert into 1-PAO and 2-PAO through consecutive hydrogenolysis reaction, ${ }^{27}$ the PAO selectivity is just about $1 / 3$ of that 2-MTHF, and it seems to be independent of the substrates (Table 2, entries 1, 3, and 4). This indicates that PAO and 2MTHF are both thermodynamically stable products with a molar ratio of $\approx 1 / 3$ at $230^{\circ} \mathrm{C}$. This is confirmed by the mutual transformation of PAO and 2-MTHF in the presence of $\mathrm{H}_{2}$ with a very high selectivity. Table 2 shows that both 1-PAO and 2-PAO can dehydrogenate to 2 -MTHF with a selectivity $>91 \%$, while 2 MTHF almost completely hydrogenate to PAO, although their conversions were $<8.5 \%$ (entries $5-7$ ).

Based on the above experimental results, a possible reaction pathway for the hydrogenation of $\mathrm{EL}$ on $\mathrm{Co} / \mathrm{ZrO}_{2}$ catalyst, as shown in Scheme 1, is proposed in combination with previous researches. ${ }^{25,28}$ First, EL quickly hydrogenates to EHP on active Co species. Then, the acid sites on the $\mathrm{ZrO}_{2}$ support catalyze dealcoholization of EHP to GVL, which is further hydrogenated to 1,4-PDO. Finally, 2-MTHF is formed through the dehydration of two hydroxyl species of 1,4-PDO. With respect to PAO, it is generated by hydrogenolysis of $1,4-\mathrm{PDO}$, and reaches a thermodynamic balance with 2-MTHF.

\subsection{Effect of solvent on EL hydrogenation to GVL}

The choice of suitable solvent is very important from viewpoints of catalytic performance, environment and upscaling. ${ }^{29}$ Table 3 shows the reaction results of solvent effect and Co leaching percentage occurred in the hydrogenation of EL to GVL over Co/ $\mathrm{ZrO}_{2}$ under optimal conditions. Clearly, water as solvent gave not only high EL conversion of $97.4 \%$ but also high GVL yield of $91.8 \%$. In contrast, benzene caused the catalyst nearly inactive. Ethanol, 1-propanol, 1-butanol, cyclohexane and 1,4-dioxane exhibited a GVL yield of $80-87 \%$ despite that EL was nearly completely converted. Concerning methanol, 2-propanol and 1pentanol solvents, both moderate EL conversion and GVL yield were obtained. This is partially due to the different solubility of $\mathrm{H}_{2}$ in different solvents. The Henry's law constants $\left(k_{\mathrm{h}}\right) \ddagger$ of $\mathrm{H}_{2}$ in methanol, ethanol, 1-propanol and 1-butanol are 596, 452, 408 and $358 \mathrm{MPa}$, respectively, ${ }^{30}$ consequently leading to these alcohol solvents with a declined $\mathrm{H}_{2}$ concentration under the same $\mathrm{H}_{2}$ pressure. Similar result was also obtained in the LA hydrogenation with $\mathrm{Ru} / \mathrm{C}$ as catalyst in different alcohols. ${ }^{31}$ However, the Co leaching in water is severe. It was found that about $28.7 \%$ of Co leached in the reaction solution, making its

$\ddagger$ Henry's law constant, $k_{\mathrm{h}}=P\left(\mathrm{H}_{2}\right) / \chi\left(\mathrm{H}_{2}\right)$, where $P$ is $\mathrm{H}_{2}$ partial pressure and $\chi$ is the mole fraction of $\mathrm{H}_{2}$ in a given solution. 
Table 2 Catalytic results of $\mathrm{Co} / \mathrm{ZrO}_{2}$ for hydrogenation of different substrates ${ }^{a}$

\begin{tabular}{|c|c|c|c|c|c|c|c|c|}
\hline & & Substrate & Time (h) & Conv. (\%) & \multicolumn{4}{|c|}{ Selectivity (\%) } \\
\hline 2 & 190 & $5 \mathrm{mmol} \mathrm{GVL}$ & 5 & 23.9 & - & 79.6 & 17.8 & 2.7 \\
\hline 3 & 230 & $1 \mathrm{mmol} \mathrm{GVL}$ & 2 & 97.0 & - & 1.9 & 74.4 & 23.7 \\
\hline 4 & 230 & $1 \mathrm{mmol}$ 1,4-PDO & 2 & 99.3 & 0.2 & - & 75.1 & 24.7 \\
\hline 7 & 230 & $1 \mathrm{mmol} 2$-MTHF & 3 & 4.0 & n.d. & n.d. & - & $100^{d}$ \\
\hline
\end{tabular}

${ }^{a}$ Reaction conditions: $15 \mathrm{~mL}$ 1,4-dioxane, $4 \mathrm{MPa} \mathrm{H}_{2}$ and $0.1 \mathrm{~g} \mathrm{Co} / \mathrm{ZrO}_{2} .{ }^{b}$ 1-PAO selectivity. ${ }^{c}$ 2-PAO selectivity. ${ }^{d} 44.2 \%$ 1-PAO and $55.8 \%$ 2-PAO, respectively.

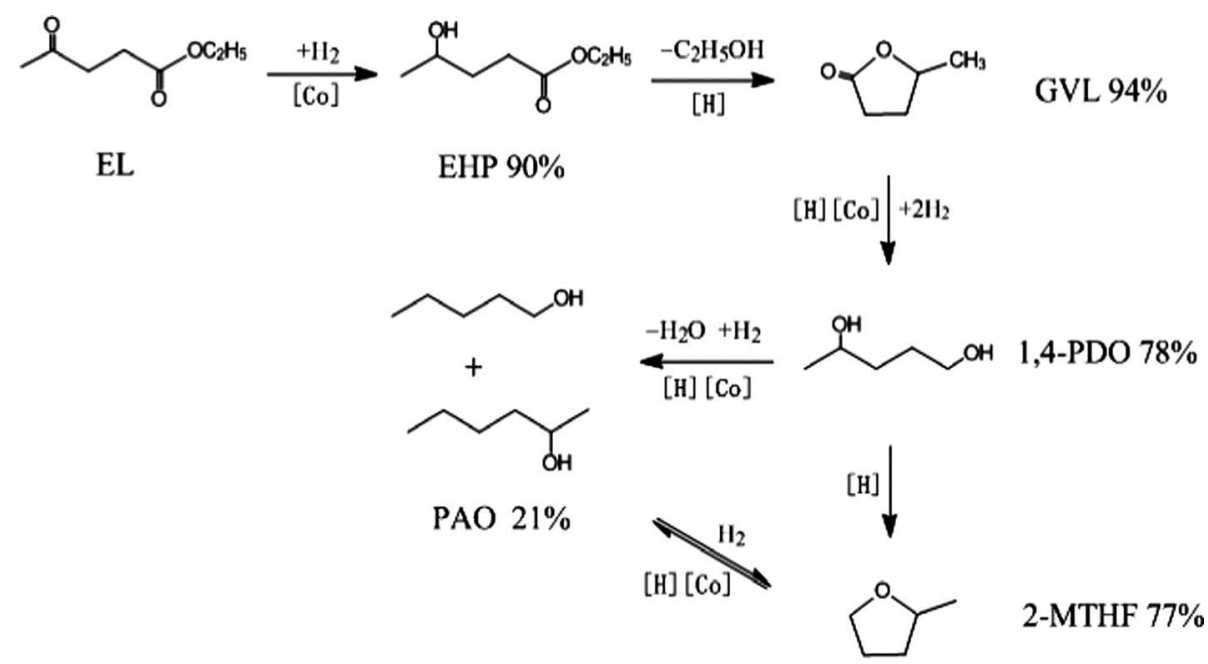

Scheme 1 Possible reaction pathway and maximum yields for the selective conversion of EL into GVL, 1,4-PDO, PAO and 2-MTHF in the presence of 1,4-dioxane.

color turning into pink as a result of formation of soluble metal carboxylate complex between $\mathrm{Co}^{2+}$ and generated levulinic acid. Similar phenomenon was observed by Hengne et $a l^{7 a}$ in the hydrogenolysis of $\mathrm{LA}$ over $\mathrm{Cu} / \mathrm{ZrO}_{2}$ in water medium. The leached copper species led to formation of blue reaction solution. The negligible activity with benzene as solvent is due to its strong adsorption on the active Co species. In contrast, the alcohol solvent has a great potential, especially when combining with the upstream processes such as production of EL from monosaccharide, polysaccharides, furfuryl alcohol, 5hydroxymethylfurfural in ethanol ${ }^{32}$ for the abatement of separation process. The utilization of alcohols has proved to be advantageous, as such solvents arguably have a relatively low net environmental impact and can be derived from biomass. ${ }^{33}$ Nonetheless, the possible etherification of alcohols with the product of 1,4-PDO make 1,4-dioxane be an appropriate solvent.

\subsection{Reusability of the $\mathrm{Co} / \mathrm{ZrO}_{2}$ catalyst}

Reusability is of great significance for heterogeneous catalysts. After reaction, $\mathrm{Co} / \mathrm{ZrO}_{2}$ can be simply separated by a magnet (Fig. $\mathrm{S} 5 \dagger$ ). $\mathrm{Co} / \mathrm{ZrO}_{2}$ shows high catalytic stability. It gave a GVL yield higher than $83.5 \%$ within 12 repeated runs with regeneration before starting the fifth recycle by calcining in air and reducing with $\mathrm{H}_{2}$ at $500{ }^{\circ} \mathrm{C}$ for $2 \mathrm{~h}$ respectively (Fig. 5). An increase in the calcination temperature to $550{ }^{\circ} \mathrm{C}$ led to a decrease of GVL yield to about $83 \%$, but it gradually increased

Table 3 Catalytic results of $\mathrm{Co} / \mathrm{ZrO}_{2}$ for hydrogenation of $\mathrm{EL}$ in different solvents ${ }^{a}$

\begin{tabular}{lllll}
\hline Entry & Solvent & $\begin{array}{l}\text { EL conv. } \\
(\%)\end{array}$ & $\begin{array}{l}\text { GVL yield } \\
(\%)\end{array}$ & $\begin{array}{l}\text { Co leaching } \\
(\%)\end{array}$ \\
\hline 1 & Water & 97.4 & 91.8 & 28.4 \\
2 & Methanol & 97.3 & 58.7 & 0.8 \\
3 & Ethanol & $>99.5$ & 84.9 & 0.8 \\
4 & 2-Propanol & 63.2 & 53.1 & 0.4 \\
5 & 1-Propanol & $>99.5$ & 84.9 & 0.2 \\
6 & 1-Butanol & $>99.5$ & 86.7 & 0.6 \\
7 & 1-Pentanol & 78.7 & 64.2 & 0.5 \\
8 & Cyclohexane & $>99.5$ & 80.0 & DNT \\
9 & Benzene & 1.0 & 0.8 & DNT \\
10 & 1,4-Dioxane & $>99.5$ & 83.5 & 0.46
\end{tabular}

${ }^{a}$ Reaction conditions: $17.4 \mathrm{mmol} \mathrm{EL}, 15 \mathrm{~mL}$ solvent, $190{ }^{\circ} \mathrm{C}, 4 \mathrm{MPa}_{2}$, $2 \mathrm{~h}$ and $0.1 \mathrm{~g} \mathrm{Co} / \mathrm{ZrO}_{2} \cdot{ }^{b}$ Determined by ICP. 
to $94 \%$ again, and maintained for four recycles, while 1,4-PDO yield gradually declined and approached zero.

To investigate the reason inducing the change of GVL yield in the repeated runs, the reduced and used catalysts were comprehensively characterized with TEM, XPS, TG and IR techniques. Fig. S6† shows that the morphology and particle size of $\mathrm{Co} / \mathrm{ZrO}_{2}$ were kept intact during the reduction and the first three recycles. The peak at $781.5 \mathrm{eV}$ in the XPS is attributed to $\mathrm{Co}^{2+/ 3+} 2 \mathrm{p}_{3 / 2}$ configuration, while that at $797 \mathrm{eV}$ is assigned to $\mathrm{Co}^{2+/ 3+} 2 \mathrm{p}_{1 / 2}$. The weak ones at $786.8 \mathrm{eV}$ and $803.5 \mathrm{eV}$ are the shake-up peaks of $\mathrm{Co}^{2+/ 3+} 2 \mathrm{p}_{3 / 2}$ and $\mathrm{Co}^{2+/ 3+} 2 \mathrm{p}_{1 / 2}$. The $\mathrm{Co}^{0} 2 \mathrm{p}_{3 / 2}$ and $\mathrm{Co}^{0} 2 \mathrm{p}_{1 / 2}$ are characterized by the peaks at 779.8 and 795.4 eV respectively. ${ }^{\mathbf{1 2 d , 3 4}}$ The $\mathrm{Co}^{\circ} / \mathrm{Co}$ ratio was kept constant in

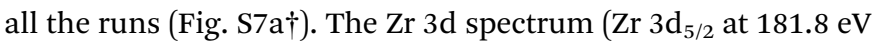
and $\mathrm{Zr} 3 \mathrm{~d}_{3 / 2}$ at $184.2 \mathrm{eV}$ with a splitting of $\left.2.4 \mathrm{eV}\right)^{35}$ did not significantly change in the spectral feature and the peak intensity after reduction and the first three recycles, revealing that $\mathrm{ZrO}_{2}$ was not reduced in the reaction system (Fig. $\mathrm{S} 7 \mathrm{~b} \dagger$ ), which is supported by the unchange of $\mathrm{O} 1 \mathrm{~s}$ peak (Fig. S7c $\dagger$ ). The major component of $\mathrm{O}(\mathrm{I})$ corresponds to $\mathrm{ZrO}_{2}(529.9 \mathrm{eV})$, and the components $\mathrm{O}$ (II) $(531.6 \mathrm{eV})$ and $\mathrm{O}$ (III) $(533.3 \mathrm{eV})$ are related to the organic or hydroxylic $\mathrm{O}$ and adsorbed water, respectively. ${ }^{35}$ The high stability of $\mathrm{ZrO}_{2}$ support was also observed in the hydrogenation of LA over $\mathrm{Ru} / \mathrm{ZrO}_{2} \cdot{ }^{35}$

Fig. 6A shows that the weight loss of $\mathrm{Co} / \mathrm{ZrO}_{2}$ in $450-600{ }^{\circ} \mathrm{C}$ is around $0.44 \%, 1.41 \%$ and $4.13 \%$ after one, two and three repeated runs, respectively. This is accompanied by the gradual increase in the GVL yield and the decrease in the 1,4-PDO yield although the EL conversion is still higher than 99\%. When the sample was regenerated by calcining at $550{ }^{\circ} \mathrm{C}$ for $2 \mathrm{~h}$ in static air and reducing with $\mathrm{H}_{2}$ at $500{ }^{\circ} \mathrm{C}$ for $2 \mathrm{~h}$ after four repeated runs, the catalytic performance was completely recovered, and showed similar changes with increasing repeated runs (Fig. 5, repeated runs 5-10).

Interestingly, when the reaction temperature was lowered down to $140{ }^{\circ} \mathrm{C}$, the EL conversion almost linearly decreased

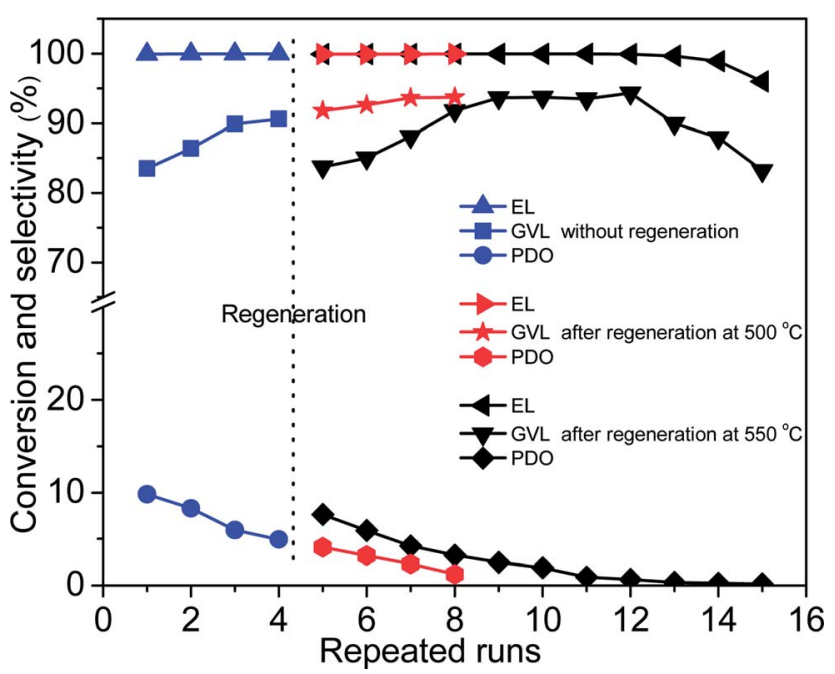

Fig. 5 Reusability tests of $\mathrm{Co} / \mathrm{ZrO}_{2}$ for hydrogenation of $\mathrm{EL}$ with regeneration after four repeated runs (reaction conditions: $17.4 \mathrm{mmol}$ $\mathrm{EL}, 15 \mathrm{~mL}$ 1,4-dioxane, $190{ }^{\circ} \mathrm{C} ; 4 \mathrm{MPa} \mathrm{H} \mathrm{H}_{2} 2 \mathrm{~h}$ and $\left.0.1 \mathrm{~g} \mathrm{Co} / \mathrm{ZrO}_{2}\right)$.
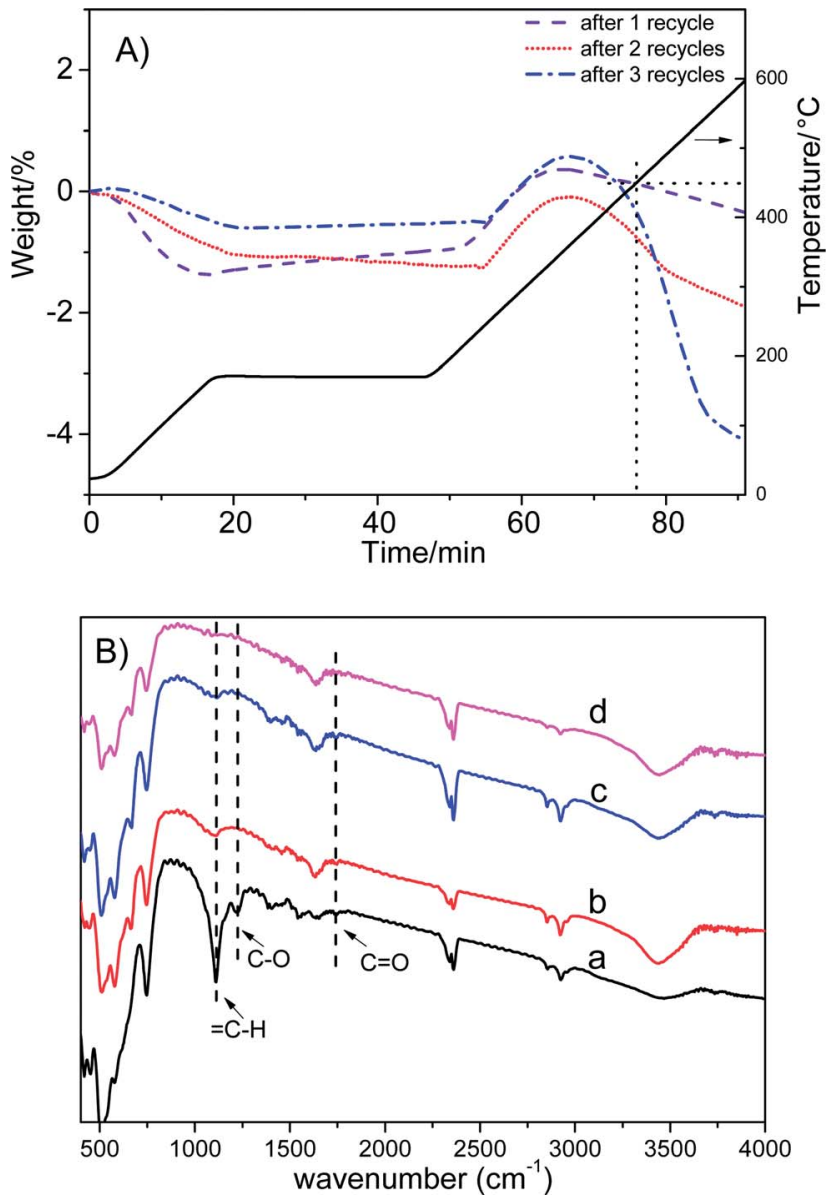

Fig. 6 (A) TG profiles of $\mathrm{Co} / \mathrm{ZrO}_{2}$ used for $1-3$ recycles; (B) FTIR spectra of spent $\mathrm{Co} / \mathrm{ZrO}_{2}$ (a), $\mathrm{Co} / \mathrm{ZrO}_{2}$ regenerated at $500{ }^{\circ} \mathrm{C}$ in air (b), $\mathrm{Co} / \mathrm{ZrO}_{2}$ regenerated at $550{ }^{\circ} \mathrm{C}$ in air (c), reduced $\mathrm{Co} / \mathrm{ZrO}_{2}$ (d).

with increasing repeated runs although the product selectivity was kept nearly the same (Fig. S8†). This shows that the hydrogenation activity of $\mathrm{Co} / \mathrm{ZrO}_{2}$ declines with the recycles maybe due to deposition of coke species on some active Co sites. Consequently, the over-hydrogenation of GVL to 1,4-PDO was suppressed, thus increasing GVL selectivity. It is unexpected that regeneration of the sample by calcining at $500{ }^{\circ} \mathrm{C}$ in static air gave a GVL yield same as that attained over the sample at 4 th recycles, being about $94 \%$. This reveals that the deposited coke species cannot be completely removed by calcining at $500{ }^{\circ} \mathrm{C}$. Thus, the decrease in both EL conversion and GVL selectivity (Fig. 5, repeated runs 13-15) can be accounted for by deposition of too many coke species on the $\mathrm{Co} / \mathrm{ZrO}_{2}$, which results in a significant decrease of acid sites. More EHP was not converted in the reaction system (a selectivity up to 16\% after 15 repeat runs), and it resulted in a decline of GVL yield.

Weckhuysen et al. reported that angelica lactone (AL) might be involved in the formation of coke species in the hydrogenation of levulinic acid. ${ }^{36}$ However, no $\mathrm{AL}$ was detected in the products and the extracted organic species from used catalyst. Zhang et al. ${ }^{37}$ found that AL dimers and trimers were generated through $\mathrm{C}-\mathrm{C}$ bond coupling in the presence of moderately strong alkalis such as $\mathrm{K}_{2} \mathrm{CO}_{3}$ and $\mathrm{Na}_{2} \mathrm{CO}_{3}$. As we know, $\mathrm{ZrO}_{2}$ is 
an acid-base amphoteric oxide. ${ }^{38}$ Thus, it is possible that dimerization and/or trimerization of AL may occur. To prove this point, the organic species occluded in used catalyst were extracted with MIBK and analyzed by the negative-ion ESI mass spectroscopy. Indeed, the mass signals typical of AL dimers and trimers were observed (Fig. S9†). This is supported by the appearance of vibration bands attributed to $=\mathrm{C}-\mathrm{H}, \mathrm{C}-\mathrm{O}$ and $\mathrm{C}=\mathrm{O}$ groups in the FT-IR spectrum (Fig. 6B). ${ }^{39}$ Another evidence was obtained by the following experiment. First, a very small amount of $\alpha$-AL (3.5 mg) was added in the reactor together with $\mathrm{Co} / \mathrm{ZrO}_{2}$ and 1,4-dioxane, and reacted for $1 \mathrm{~h}$ under the conditions ( $2 \mathrm{MPa} \mathrm{N}_{2}, 80{ }^{\circ} \mathrm{C}$ ) typical for formation of dimers and trimers. ${ }^{35}$ Then, $2.51 \mathrm{~g}$ EL was added after cooling to room temperature and reacted under the above normal conditions, which gave a GVL yield of $87.8 \%$, being similar to the GVL yield in the third recycle (Fig. 5). Thus, it can be deduced that $\mathrm{AL}$ dimers and trimers are the coke species deposited on the $\mathrm{Co} /$ $\mathrm{ZrO}_{2}$ in the hydrogenation of EL.

Table $\mathrm{S} 1 \uparrow$ compares the catalytic results for the hydrogenation of LA and its ester to GVL over $\mathrm{Co} / \mathrm{ZrO}_{2}$ and reported catalysts. The commercial $\mathrm{Ru} / \mathrm{C}$ shows the best catalytic performance for the hydrogenation of LA. ${ }^{31}$ In contrast, Cubased and Co-based catalysts and RANEY® Ni exhibit a GVL selectivity of $80-90 \%$ except for metallic Co and $4 \mathrm{Co} / \mathrm{Al}_{2} \mathrm{O}_{3}$ prepared by calcining corresponding hydrotalcite at $700{ }^{\circ} \mathrm{C}$, on which about $94 \%$ of EL and $>99 \%$ of LA were hydrogenated into GVL respectively. ${ }^{7 \boldsymbol{a}, \mathbf{1 1 b}, \mathbf{1 2 c}, \mathbf{1 2 d , 4 0}}$ Regardless of this, the GVL productivity of $\mathrm{Co} / \mathrm{ZrO}_{2}$ reaches $1.5 \mathrm{~mol} \mathrm{~g}$ metal ${ }^{-1} \mathrm{~h}^{-1}$, which is much higher than that obtained over the reported non-noble metal catalysts. In addition, the GVL selectivity could be significantly increased to $94.3 \%$ with increasing repeated runs to 12 after regeneration by calcining at $550{ }^{\circ} \mathrm{C}$ for $2 \mathrm{~h}$ and reducing at $500{ }^{\circ} \mathrm{C}$ for $2 \mathrm{~h}$ before the 5 th recycle.

\section{Conclusions}

$\mathrm{Co} / \mathrm{ZrO}_{2}$ shows high activity and selectivity to GVL, 1,4-PDO or 2MTHF in the reaction of EL hydrogenation. The GVL, 1,4-PDO and 2 -MTHF reach $94 \%, 78 \%$ and $77 \%$, respectively. It is interesting that a change of the $\mathrm{ZrO}_{2}$ support to SBA-15 selectively convert EL into EHP (selectivity > 90\%) as a result of decreasing acid sites in catalyst. In addition, $\mathrm{Co} / \mathrm{ZrO}_{2}$ shows very high catalytic stability, and can be reused with regeneration by calcining at $550{ }^{\circ} \mathrm{C}$ in air. No significant leaching and coordination state changes of Co species were observed. The $\mathrm{Co} /$ $\mathrm{ZrO}_{2}$ also exhibits the highest GVL productivity, being $1.50 \mathrm{~mol}$ $\mathrm{g}_{\text {metal }}{ }^{-1} \mathrm{~h}^{-1}$, among the reported non-noble metal catalysts. The reaction conditions, including temperature, $\mathrm{H}_{2}$ pressure, time, catalysts amount and solvent, have great effect on the catalytic performance. It was found that the deposited coke species are AL dimers and trimers, which decreases the hydrogenation activity, but favors formation of GVL yield due to cover of some active Co species. It's envisaged that such an active, selective and robust catalyst will hold remarkable advantages in the EL flexible transformation.

\section{Conflicts of interest}

There are no conflicts of interest to declare.

\section{Acknowledgements}

This work is financially supported by the National Natural Science Foundation of China (21403269 and 21603254), the Natural Science Foundation of Shanxi Province (2016021033), the Science Foundation for Youth Scholars of State Key Laboratory of Coal Conversion (2016BWZ002), the Youth Innovation Promotion Association CAS (2015140) and the CAS/SAFEA International Partnership Program for Creative Research Teams (2015YC901).

\section{Notes and references}

1 P. N. Vennestrom, C. M. Osmundsen, C. H. Christensen and E. Taarning, Angew. Chem., Int. Ed., 2011, 50, 10502-10509.

2 (a) C. H. Zhou, X. Xia, C. X. Lin, D. S. Tong and J. Beltramini, Chem. Soc. Rev., 2011, 40, 5588-5617; (b) C. Chatterjee, F. Pong and A. Sen, Green Chem., 2015, 17, 40-71.

3 (a) A. M. Ruppert, K. Weinberg and R. Palkovits, Angew. Chem., Int. Ed., 2012, 51, 2564-2601; (b) A. Corma, S. Iborra and A. Velty, Chem. Rev., 2007, 107, 2411-2502; (c) P. Gallezot, Chem. Soc. Rev., 2012, 41, 1538-1558; (d) D. M. Alonso, S. G. Wettstein, M. A. Mellmer, E. I. Gurbuz and J. A. Dumesic, Energy Environ. Sci., 2013, 6, 76-80; (e) Y. Wang, S. De and N. Yan, Chem. Commun., 2016, 52, 6210-6224.

4 (a) S. Zhu, Y. Xue, J. Guo, Y. Cen, J. Wang and W. Fan, ACS Catal., 2016, 6, 2035-2042; (b) W. R. H. Wright and R. Palkovits, ChemSusChem, 2012, 5, 1657-1667; (c) D. M. Alonso, S. G. Wettstein and J. A. Dumesic, Green Chem., 2013, 15, 584-595.

5 (a) H. Chen, B. Yu and S. Jin, Bioresour. Technol., 2011, 102, 3568-3570; (b) E. I. Gürbüz, S. G. Wettstein and J. A. Dumesic, ChemSusChem, 2012, 5, 383-387; (c) F. Yu, J. Thomas, M. Smet, W. Dehaen and B. F. Sels, Green Chem., 2016, 18, 1694-1705.

6 (a) E. Ahmad, M. I. Alam, K. K. Pant and M. A. Haider, Green Chem., 2016, 18, 4804-4823; (b) S. Zhu, Y. Cen, J. Guo, J. Chai, J. Wang and W. Fan, Green Chem., 2016, 18, 5667-5675.

7 (a) A. M. Hengne and C. V. Rode, Green Chem., 2012, 14, 1064-1072; (b) W. H. Luo, P. C. A. Bruijnincx and B. M. Weckhuysen, J. Catal., 2014, 320, 33-41.

8 (a) X. Hu and C. Z. Li, Green Chem., 2011, 13, 1676-1679; (b) S. Zhu, J. Guo, X. Wang, J. Wang and W. Fan, ChemSusChem, 2017, 10, 2547-2559.

9 (a) A. D. Chowdhury, R. Jackstell and M. Beller, ChemCatChem, 2014, 6, 3360-3365; (b) U. Omoruyi, S. Page, J. Hallett and P. W. Miller, ChemSusChem, 2016, 9, 20372047.

10 (a) W. Luo, M. Sankar, A. M. Beale, Q. He, C. J. Kiely, P. C. Bruijnincx and B. M. Weckhuysen, Nat. Commun., 2015, 6, 6540; (b) S. Cao, J. R. Monnier and J. R. Regalbuto, J. Catal., 2017, 347, 72-78. 
11 (a) C. Xie, J. L. Song, B. W. Zhou, J. Y. Hu, Z. R. Zhang, P. Zhang, Z. W. Jiang and B. X. Han, ACS Sustainable Chem. Eng., 2016, 4, 6231-6236; (b) M. Chia and J. A. Dumesic, Chem. Comm., 2011, 47, 12233-12235; (c) Z. Yang, Y. B. Huang, Q. X. Guo and Y. Fu, Chem. Comm., 2013, 49, 5328-5330; (d) A. H. Valekar, K. H. Cho, S. K. Chitale, D.-Y. Hong, G. Y. Cha, U. H. Lee, D. W. Hwang, C. Serre, J. S. Chang and Y. K. Hwang, Green Chem., 2016, 18, 4542-4552; J. Wang, S. Jaenicke and G. K. Chuah, RSC Adv., 2014, 4, 13481-13489.

12 (a) V. Mohan, V. Venkateshwarlu, C. V. Pramod, B. D. Raju and K. S. R. Rao, Catal.Sci. Technol., 2014, 4, 1253-1259; (b) K. Jiang, D. Sheng, Z. H. Zhang, J. Fu, Z. Y. Hou and X. Y. Liu, Catal. Today, 2016, 274, 55-59; (c) K. Yan and A. C. Chen, Fuel, 2014, 115, 101-108; (d) H. C. Zhou, J. L. Song, H. L. Fan, B. B. Zhang, Y. Y. Yang, J. Y. Hu, Q. G. Zhu and B. X. Han, Green Chem., 2014, 16, 3870-3875. 13 (a) A. Diaz-Rodriguez, W. Borzecka, I. Lavandera and V. Gotor, ACS Catal., 2014, 4, 386-393; (b) A. Manzocchi, R. Casati, A. Fiecchi and E. Santaniello, J. Chem. Soc., Perkin Trans. 1, 1987, 2753-2757.

14 (a) F. M. Geilen, B. Engendahl, A. Harwardt, W. Marquardt, J. Klankermayer and W. Leitner, Angew. Chem., Int. Ed., 2010, 49, 5510-5514; (b) M. Pagliaro, R. Ciriminna, H. Kimura, M. Rossi and C. DellaPina, Angew. Chem., Int. Ed., 2007, 46, 4434-4440; (c) Y. Shen, B. B. Yao, G. Yu, Y. Fu, F. S. Liu and Z. B. Li, Green Chem., 2017, 19, 4930-4938.

15 A. Phanopoulos, A. J. P. White, N. J. Long and P. W. Miller, ACS Catal., 2015, 5, 2500-2512.

16 H. Mehdi, V. Fabos, R. Tuba, A. Bodor, L. T. Mika and I. T. Horvath, Top. Catal., 2008, 48, 49-54.

17 (a) Z. Wang, G. Li, X. Liu, Y. Huang, A. Wang, W. Chu, X. Wang and N. Li, Catal. Commun., 2014, 43, 38-41; (b) M. X. Li, G. Y. Li, N. Li, A. Q. Wang, W. J. Dong, X. D. Wang and Y. Cong, Chem. Comm., 2014, 50, 14141416; (c) L. Corbel-Demailly, B. K. Ly, D. P. Minh, B. Tapin, C. Especel, F. Epron, A. Cabiac, E. Guillon, M. Besson and C. Pinel, ChemSusChem, 2013, 6, 2388-2395; (d) T. Mizugaki, Y. Nagatsu, K. Togo, Z. Maeno, T. Mitsudome, K. Jitsukawa and K. Kaneda, Green Chem., 2015, 17, 51365139.

18 T. Mizugaki, K. Togo, Z. Maeno, T. Mitsudome, K. Jitsukawa and K. Kaneda, ACS Sustainable Chem. Eng., 2016, 4, 682685.

19 Y. Yang, X. Xu, W. Zou, H. Yue, G. Tian and S. Feng, Catal. Commun., 2016, 76, 50-53.

20 A. Martínez, C. López, F. Márquez and I. Díaz, J. Catal., 2003, 220, 486-499.

21 (a) M. Audemar, C. Ciotonea, K. De Oliveira Vigier, S. Royer, A. Ungureanu, B. Dragoi, E. Dumitriu and F. Jérôme, ChemSusChem, 2015, 8, 1885-1891; (b) A. Ungureanu, B. Dragoi, A. Chirieac, S. Royer, D. Duprez and E. Dumitriu, J. Mater. Chem., 2011, 21, 12529-12541.

22 K. Cheng, V. Subramanian, A. Carvalho, V. V. Ordomsky, Y. Wang and A. Y. Khodakov, J. Catal., 2016, 337, 260-271.

23 J. M. Nadgeri, N. Hiyoshi, A. Yamaguchi, O. Sato and M. Shirai, Appl. Catal., A, 2014, 470, 215-220.
24 F. Ye, D. Zhang, T. Xue, Y. Wang and Y. Guan, Green Chem., 2014, 16, 3951-3957.

25 X. Du, Q. Bi, Y. Liu, Y. Cao, H. He and K. Fan, Green Chem., 2012, 14, 935-939.

26 (a) P. Sun, G. Gao, Z. Zhao, C. Xia and F. Li, ACS Catal., 2014, 4, 4136-4142; (b) K. Kon, W. Onodera and K. Shimizu, Catal. Sci. Technol., 2014, 4, 3227-3234; (c) T. Pan, J. Deng, Q. Xu, Y. Xu, Q. X. Guo and Y. Fu, Green Chem., 2013, 15, 29672974.

27 S. Zhu, X. Gao, Y. Zhu, Y. Zhu, X. Xiang, C. Hu and Y. Li, Appl. Catal., B, 2013, 140, 60-67.

28 (a) A. Villa, M. Schiavoni, C. E. Chan-Thaw, P. F. Fulvio, R. T. Mayes, S. Dai, K. L. More, G. M. Veith and L. Prati, ChemSusChem, 2015, 8, 2520-2528; (b) T. Pan, J. Deng, Q. Xu, Y. Xu, Q. X. Guo and Y. Fu, Green Chem., 2013, 15, 2967-2974; (c) D. Zhang, F. Ye, Y. Guan, Y. Wang and E. J. M. Hensen, RSC Adv., 2014, 4, 39558-39564.

29 (a) J. G. Zhang and N. Yan, ChemCatChem, 2017, 9, 27902796; (b) X. Hu, R. J. M. Westerhof, D. H. Dong, L. P. Wu and C. Z. Li, ACS Sustainable Chem. Eng., 2014, 2, 2562-2575.

30 (a) Purwanto, R. M. Deshpande, R. V. Chaudhari and H. Delmas, J. Chem. Eng. Data, 1996, 41, 1414-1417; (b) M. S. Wainwright, T. Ahn, D. L. Trimm and N. W. Cant, J. Chem. Eng. Data, 1987, 32, 22-24.

31 M. G. Al-Shaal, W. R. H. Wright and R. Palkovits, Green Chem., 2012, 14, 1260-1263.

32 (a) G. Pasquale, P. Vázquez, G. Romanelli and G. Baronetti, Catal. Commun., 2012, 18, 115-120; (b) S. Saravanamurugan and A. Riisager, ChemCatChem, 2013, 5, 1754-1757; (c) R. Liu, J. Chen, X. Huang, L. Chen, L. Ma and X. Li, Green Chem., 2013, 15, 2895-2903; (d) B. Lu, S. An, D. Song, F. Su, X. Yang and Y. Guo, Green Chem., 2015, 17, 1767-1778.

33 M. Fatih Demirbas, M. Balat and H. Balat, Energy Convers. Manage., 2011, 52, 1815-1828.

34 (a) B. Ernst, S. Libs, P. Chaumette and A. Kiennemann, Appl. Catal., A, 1999, 186, 145-168; (b) T. Cai, H. Huang, W. Deng, Q. Dai, W. Liu and X. Wang, Appl. Catal., B, 2015, 166, 393405.

35 J. Ftouni, A. Muñoz-Murillo, A. Goryachev, J. P. Hofmann, E. J. M. Hensen, L. Lu, C. J. Kiely, P. C. A. Bruijnincx and B. M. Weckhuysen, ACS Catal., 2016, 6, 5462-5472.

36 W. H. Luo, U. Deka, A. M. Beale, E. R. H. van Eck, P. C. A. Bruijnincx and B. M. Weckhuysen, J. Catal., 2013, 301, 175-186.

37 J. Xin, S. Zhang, D. Yan, O. Ayodele, X. Lu and J. Wang, Green Chem., 2014, 16, 3589-3595.

38 K. Tanabe and T. Yamaguchi, Catal. Today, 1994, 20, 185198.

39 T. Chen, Z. Qin, Y. Qi, T. Deng, X. Ge, J. Wang and X. Hou, Polym. Chem., 2011, 2, 1190-1194.

40 (a) Q. Xu, X. L. Li, T. Pan, C. G. Yu, J. Deng, Q. X. Guo and Y. Fu, Green Chem., 2016, 18, 1287-1294; (b) X. D. Long, P. Sun, Z. L. Li, R. Lang, C. G. Xia and F. W. Li, Chin. J. Catal., 2015, 36, 1512-1518. 